\title{
Effect of Rectal Prolapse Surgery on Patients' Gastrointestinal Quality of Life
}

Kiliç Erol*, Uğur Mustafa

General Surgery Department Hatay Mustafa Kemal University Medical School Turkey

DOI: $10.36347 /$ sjams.2020.v08i10.034

| Received: 15.10 .2020 | Accepted: 23.10.2020 | Published: 28.10.2020

*Corresponding author: Erol Kiliç

Abstract

Original Research Article

Rectal prolapse (RP) is a clinical condition causing reduced quality of life and is commonly treated via transabdominal and transanal approaches. The retrospective study included RP patients that were operatively treated via open or laparoscopic approach in our clinic between January 2016 and January 2020. In both groups, Gastrointestinal Quality of Life Index (GIQLI) was administered at postoperative week 1 and month 6 to assess patients' health-related quality of life. The GIQLI scores at week 1 were significantly higher in the laparoscopic group $(p<0.001)$, while no significant difference was found at month $6(p>0.001)$. Both open and laparoscopic approaches led to a significant improvement in patients' quality of life and this improvement occurred at an earlier time in the laparoscopic group compared to the open group.

Keywords: Rectal prolapse (RP), transanal approaches, Gastrointestinal Quality of Life Index (GIQLI).

Copyright $\odot 2020$ The Author(s): This is an open-access article distributed under the terms of the Creative Commons Attribution 4.0 International License (CC BY-NC 4.0) which permits unrestricted use, distribution, and reproduction in any medium for non-commercial use provided the original author and source are credited.

\section{INTRODUCTION}

Rectal prolapse (RP), is defined as the protrusion of the layers of the rectal wall through the anal canal. Although the exact etiology of RP remains unknown, various factors including redundant sigmoid colon, pelvic floor changes, and relaxation of lateral ligaments have been blamed. These factors, in turn, are considered to cause pudental neuralgia, thereby resulting in anal incontinence $[1,2]$.

Surgery is the mainstay treatment of RP and numerous surgical techniques have been described to date. The primary aim in surgical treatment is to prevent the protrusion of the rectum and sigmoid colon segments, to discharge the rectum without causing constipation, and to prevent incontinence. The choice of surgical technique depends on the experience and discretion of the surgeon and on the presence of comorbidities, constipation, and incontinence [1]. Currently, surgical treatment of RP is performed via open or laparoscopic approaches.

The aim of this study was to investigate the effect of open and laparoscopic approaches on earlyand late-term quality of life of RP patients using Gastrointestinal Quality of Life Index (GIQLI).

\section{MATERIALS AND METHODS}

The retrospective study included RP patients that were operatively treated via open or laparoscopic approach in our clinic between January 2016 and January 2020. Patients that underwent transanal surgeries, refused to participate in the study, had malignant and inflammatory bowel diseases, and one patient that developed recurrence four months after laparoscopic surgery were excluded from the study. Severity of RP was graded based on physical examination findings and the methods performed in previous studies (Table 1) [2].

Prior to the surgical procedure, bowel cleansing was performed using rectal enema and colonoscopy was performed to rule out additional diseases. Open surgical techniques included sigmoid colon resection and rectopexy. Rectopexy was performed by fixing the rectum to the sacrum using polypropylene sutures or synthetic polypropylene meshes. In patients with a redundant sigmoid colon and constipation, the rectum was freed completely and then sigmoid resection followed by end-to-end anastomosis was performed. Subsequently, rectopexy was performed after fixing the rectum to the sacrum with polypropylene sutures. In patients that did not require resection, the rectum was freed completely and then a polypropylene synthetic mesh was placed in the sacral space and sutured to the rectum in such a way that $1 / 3$ 
of the anterior rectal wall was left open. Afterwards, rectopexy was performed after fixing the mesh to the sacrum with polypropylene sutures. All these procedures were performed by experienced surgeons using either open and laparoscopic approach.

Patients were divided into two groups based on the surgical technique performed: open and laparoscopic. Age, gender, wound site infection, seroma, recurrence, operative time, and mortality rate were compared between the two groups. In both groups, GIQLI was administered at postoperative week 1 and month 6 to assess patients' health-related quality of life, using the criteria defined by Eypasch et al. For each patient, a total of 36 parameters were evaluated and the scores were calculated based on a five-point Likert scale (0-4; 0: worst, 4 : best), with the total score ranging between 0 and 144 and the higher scores indicating greater postoperative recovery and higher quality of life [3].

\section{STATISTICAL ANALYSIS}

Data were analyzed using SPSS version 23.0 for Windows (IBM Corp. Released 2015, Armonk, NY: IBM Corp.). Normal distribution of data was assessed using Shapiro-Wilk test. Variables with normal distribution were compared using Student's t-test and variables with nonnormal distribution were compared using Mann-Whitney $U$ test. Descriptives were expressed as mean \pm standard deviation (SD) for continuous variables and as frequencies (n) and percentages for categorical variables. A $p$ value of $<0.05$ was considered significant.

\section{RESULTS}

The study included 31 patients, with 14 $(45.2 \%)$ patients in the laparoscopic group and 17 $(54.8 \%)$ patients in the open group. The groups were similar with regard to age and gender distribution $(p>0.05)$. Although the incidence of wound site complications such as seroma, infection, and wound dehiscence was greater in the open group, no significant difference was established ( $\mathrm{p}>0.05)$ (Table 2).
The GIQLI scores assessed at postoperative week 1 were significantly higher in the laparoscopic group $(p<0.001)$, while no significant difference was found between the two groups with regard to the GIQLI scores assessed at postoperative month 6 $(p>0.001)($ Table 3-4).

Postoperativeweek 1 (Table 3): One of the core symptoms, abdominal pain, had a significantly lower score in the open group $(2.26 \pm 1.06)$ compared to the laparoscopic group $(3.48 \pm 0.64)(p<0.001)$. Similarly, the scores of other core symptoms were significantly lower in the open group compared to the laparoscopic group $(p<0.001)$.

The scores of GIQLI-physical items including physical strength and appearance were significantly higher in the laparoscopic group compared to the open group $(p<0.001)$. However, no significant difference was found with regard to the scores of other physical items $(p>0.001)$.

The scores of all GIQLI-emotional items were significantly higher in the laparoscopic group $(p<0.001)$. The scores of GIQLI-social items including daily activities and personal relationship were significantly higher in the laparoscopic group compared to the open group $(p<0.001)$, whereas no significant difference was found with regard to leisure activities and sexual life $(p>0.001)$.

Among disease-related symptoms, the incidence of nausea, diarrhea, and fecal incontinence was similar in both groups $(p>0.001)$, whereas the incidence of other findings was significantly higher in the laparoscopic group compared to the open group $(p<0.001)$.

The total GIQLI score was significantly higher in the laparoscopic group compared to the open group $(122.89 \pm 3.34 v s .84 .48 \pm 6.19)(p<0.001)$.

PostoperativeMonth6 (Table 4): No significant difference was found between the two groups with regard to the scores of GIQLI items and total GIQLI score $(121.89 \pm 6.34$ vs. $126.91 \pm 7.34)(p>0.001)$.

Table-1: Grading of rectalprolapse

\begin{tabular}{|l|l|}
\hline Grade 1 & Mukozalprolapse \\
\hline Grade 2 & Intussusception of rectum or rectosigmoid junction \\
\hline Grade 3 & Completeprolapse \\
\hline
\end{tabular}


Table-2: Demographic and postoperative clinical characteristics

\begin{tabular}{|l|l|l|l|}
\hline & $\begin{array}{l}\text { Open surgery } \\
(\mathbf{n = 1 7 )}\end{array}$ & $\begin{array}{l}\text { Laparoscopic surgery } \\
(\mathbf{n = 1 4})\end{array}$ & $\boldsymbol{p}$ \\
\hline Age (years, median) & $67(51-77)$ & $64(48-74)$ & $>0.05$ \\
\hline $\begin{array}{l}\text { Gender, n(\%) } \\
\text { Female }\end{array}$ & $12(70.6)$ & $11(78.6)$ \\
Male & $5(29.4)$ & $3(21.4)$ & $>0.05$ \\
\hline $\begin{array}{l}\text { Time to firstgas/stool discharge (days, } \\
\text { median) }\end{array}$ & $4(2-5)$ & $2(1-4)$ & $<0.05$ \\
\hline Operative Time (minutes, median) & $66(43-98)$ & $114(78-134)$ & $<0.05$ \\
\hline Wound site complications (n, \%) & $3(17)$ & $1(7,1)$ & $>0.05$ \\
\hline Hospital stay (days, median) & $5(3-8)$ & $3(1-6)$ & $>0.05$ \\
\hline
\end{tabular}

Table-3: Gastrointestinal Quality of Life Index (GIQLI) scores - Postoperativeweek 1

\begin{tabular}{|c|c|c|c|}
\hline & Abdominal-Open & Laparoscopic & $p^{*}$ \\
\hline \multicolumn{4}{|l|}{ Coresymptoms } \\
\hline Abdominal Pain & $2.26 \pm 1.06$ & $3.48 \pm 0.64$ & $<0.001$ \\
\hline Abdominal fullness & $2.07 \pm 1.03$ & $3.37 \pm 0.74$ & $<0.001$ \\
\hline Abdominal bloating & $2.37 \pm 1.08$ & $3.33 \pm 0.83$ & 0.001 \\
\hline Flatulence & $2.48 \pm 1.05$ & $3.56 \pm 0.51$ & $<0.001$ \\
\hline Belching & $2.11 \pm 0.75$ & $3.48 \pm 0.58$ & $<0.001$ \\
\hline Defecation & $1.89 \pm 0.64$ & $3.26 \pm 0.59$ & $<0.001$ \\
\hline Abdominal noises & $2.74 \pm 0.76$ & $3.67 \pm 0.55$ & $<0.001$ \\
\hline Restricted eating & $2.11 \pm 0.85$ & $3.44 \pm 0.58$ & $<0.001$ \\
\hline Enjoyed eating & $2.37 \pm 0.88$ & $3.52 \pm 0.64$ & $<0.001$ \\
\hline Fatigue & $1.67 \pm 0.96$ & $3.56 \pm 0.58$ & $<0.001$ \\
\hline \multicolumn{4}{|l|}{ Physical items } \\
\hline Physical strength & $1.74 \pm 0.59$ & $3.22 \pm 0.58$ & ns \\
\hline Feeling unwell & $1.73 \pm 0.83$ & $3.15 \pm 0.67$ & $<0.001$ \\
\hline Feeling unfit & $2.11 \pm 0.75$ & $3.37 \pm 0.63$ & $\mathrm{~ns}$ \\
\hline Endurance & $2.96 \pm 0.59$ & $3.41 \pm 0.57$ & ns \\
\hline Wake-up at night & $2.04 \pm 0.65$ & $3.63 \pm 0.49$ & ns \\
\hline Appearance & $1.52 \pm 0.80$ & $3.41 \pm 0.64$ & $<0.001$ \\
\hline \multicolumn{4}{|l|}{ Emotional items } \\
\hline Sadness & $2.33 \pm 0.62$ & $3.52 \pm 0.58$ & $<0.001$ \\
\hline Nervousness & $2.04 \pm 1.19$ & $3.59 \pm 0.69$ & $<0.001$ \\
\hline Frustration & $2.44 \pm 0.70$ & $3.56 \pm 0.51$ & $<0.001$ \\
\hline Happiness & $2.41 \pm 0.89$ & $3.33 \pm 0.55$ & $<0.001$ \\
\hline Bothered by treatment & $2.59 \pm 0.69$ & $3.22 \pm 0.64$ & $<0.001$ \\
\hline Coping with stress & $2.41 \pm 0.80$ & $3.33 \pm 0.62$ & $<0.001$ \\
\hline \multicolumn{4}{|l|}{ Social items } \\
\hline Daily activities & $1.96 \pm 0.65$ & $3.33 \pm 0.62$ & $<0.001$ \\
\hline Leisure activities & $2.89 \pm 0.70$ & $3.30 \pm 0.47$ & $\mathrm{~ns}$ \\
\hline Sexual life & $2.74 \pm 0.71$ & $2.93 \pm 0.55$ & ns \\
\hline Personal relationship & $2.19 \pm 0.68$ & $3.48 \pm 0.51$ & $<0.001$ \\
\hline \multicolumn{4}{|l|}{ Disease-related symptoms } \\
\hline Regurgitation & $2.26 \pm 0.81$ & $3.48 \pm 0.51$ & $<0.001$ \\
\hline Dysphagia & $2.37 \pm 0.74$ & $3.48 \pm 0.51$ & $<0.001$ \\
\hline Eating speed & $2.18 \pm 0.68$ & $3.11 \pm 0.51$ & $<0.001$ \\
\hline Nausea & $3.26 \pm 0.66$ & $3.56 \pm 0.50$ & ns \\
\hline Diarrhea & $2.93 \pm 0.67$ & $3.44 \pm 0.50$ & $\mathrm{~ns}$ \\
\hline Bowel urgency & $3.07 \pm 0.67$ & $3.63 \pm 0.49$ & $<0.001$ \\
\hline Constipation & $2.15 \pm 0.60$ & $3.41 \pm 0.50$ & $<0.001$ \\
\hline Blood in stool & $2.48 \pm 0.80$ & $3.56 \pm 0.51$ & $<0.001$ \\
\hline Heartburn & $2.52 \pm 0.51$ & $3.52 \pm 0.51$ & $<0.001$ \\
\hline Fecal incontinence & $3.11 \pm 0.58$ & $3.37 \pm 0.49$ & ns \\
\hline Total GIQLIscore & $84.48 \pm 6.19$ & $122.89 \pm 3.34$ & $<0.001$ \\
\hline \multicolumn{4}{|c|}{$\begin{array}{l}\text { Data wasgivenmean } \pm \mathrm{SD}, \mathrm{ns}: \text { notsignificant } \\
\text { Bold } p \text { valuesshow statisticalsignificance }(p<0.05) \\
\mathrm{P} \text { valuewasobtainedfromStudent's t-test and Mann-Whitney U test } \\
\text { *: Student's t-test and Mann-Whitney U test }\end{array}$} \\
\hline
\end{tabular}


Table-4: Gastrointestinal Quality of Life Index (GIQLI) scores - Postoperative month 6

\begin{tabular}{|c|c|c|c|}
\hline & Abdominal-Open & Laparoscopic & $p^{*}$ \\
\hline \multicolumn{4}{|l|}{ Core symptoms } \\
\hline Abdominal Pain & $3.35 \pm 0.57$ & $3.48 \pm 0.52$ & \\
\hline Abdominal fullness & $3.24 \pm 0.67$ & $3.53 \pm 0.52$ & \\
\hline Abdominal bloating & $3.56 \pm 0.55$ & $3.36 \pm 0.5$ & \\
\hline Flatulence & $3.52 \pm 0.51$ & $3.48 \pm 0.52$ & \\
\hline Belching & $3.54 \pm 0.55$ & $3.59 \pm 0.51$ & \\
\hline Defecation & $3.26 \pm 0.57$ & $3.18 \pm 0.53$ & $>0.001$ \\
\hline Abdominal noises & $3.56 \pm 0.66$ & $3.42 \pm 0.62$ & \\
\hline Restricted eating & $3.49 \pm 0.55$ & $3.77 \pm 0.44$ & \\
\hline Enjoyed eating & $3.47 \pm 0.51$ & $3.42 \pm 0.51$ & \\
\hline Fatigue & $3.49 \pm 0.55$ & $3.53 \pm 0.63$ & \\
\hline \multicolumn{4}{|l|}{ Physical items } \\
\hline Physical strength & $3.39 \pm 0.58$ & $3.48 \pm 0.52$ & \\
\hline Feeling unwell & $3.47 \pm 0.55$ & $3.59 \pm 0.51$ & \\
\hline Feeling unfit & $3.45 \pm 0.59$ & $3.65 \pm 0.5$ & $>0.001$ \\
\hline Endurance & $3.52 \pm 0.55$ & $3.42 \pm 0.51$ & \\
\hline Wake-up at night & $3.69 \pm 0.48$ & $3.65 \pm 0.5$ & . \\
\hline Appearance & $3.49 \pm 0.59$ & $3.77 \pm 0.44$ & \\
\hline \multicolumn{4}{|l|}{ Emotional items } \\
\hline Sadness & $3.62 \pm 0.54$ & $3.59 \pm 0.51$ & \\
\hline Nervousness & $3.66 \pm 0.53$ & $3.71 \pm 0.47$ & \\
\hline Frustration & $3.54 \pm 0.66$ & $3.71 \pm 0.47$ & \\
\hline Happiness & $3.43 \pm 0.55$ & $3.59 \pm 0.51$ & $>0.001$ \\
\hline Bothered by treatment & $3.32 \pm 0.56$ & $3.36 \pm 0.71$ & \\
\hline Coping with stress & $3.49 \pm 0.55$ & $3.48 \pm 0.52$ & \\
\hline \multicolumn{4}{|l|}{ Social items } \\
\hline Daily activities & $3.73 \pm 0.46$ & $3.59 \pm 0.51$ & \\
\hline Leisure activities & $3.49 \pm 0.51$ & $3.42 \pm 0.51$ & $>0.001$ \\
\hline Sexual life & $3.43 \pm 0.55$ & $3.36 \pm 0.5$ & \\
\hline Personal relationship & $3.64 \pm 0.49$ & $3.59 \pm 0.51$ & \\
\hline \multicolumn{4}{|c|}{ Disease-related symptoms } \\
\hline Regurgitation & $3.45 \pm 0.51$ & $3.48 \pm 0.52$ & \\
\hline Dysphagia & $3.54 \pm 0.51$ & $3.53 \pm 0.52$ & \\
\hline Eating speed & $3.47 \pm 0.51$ & $3.3 \pm 0.47$ & \\
\hline Nausea & $3.64 \pm 0.49$ & $3.48 \pm 0.52$ & \\
\hline Diarrhea & $3.81 \pm 0.4$ & $3.77 \pm 0.44$ & $>0.001$ \\
\hline Bowel urgency & $3.62 \pm 0.5$ & $3.42 \pm 0.51$ & \\
\hline Constipation & $3.39 \pm 0.5$ & $3.53 \pm 0.52$ & \\
\hline Blood in stool & $3.6 \pm 0.5$ & $3.71 \pm 0.47$ & \\
\hline Heartburn & $3.71 \pm 0.47$ & $3.71 \pm 0.47$ & \\
\hline Fecal incontinence & $3.2 \pm 0.58$ & $3.42 \pm 0.62$ & \\
\hline Total GIQLI score & $121.89 \pm 6.34$ & $126.91 \pm 7.34$ & $>0.001$ \\
\hline \multicolumn{4}{|c|}{$\begin{array}{l}\text { Data was given mean } \pm \mathrm{SD} \text {, ns: not significant } \\
\text { Bold } p \text { values show statistical significance }(p<0.05) \\
\mathrm{P} \text { value was obtained from Student's t-test and Mann-Whitney U test } \\
\text { *: Student's t-test and Mann-Whitney U test }\end{array}$} \\
\hline
\end{tabular}

\section{DISCUSSION}

Although the exact incidence of RP in the general population remains unknown, this condition is commonly seen in adults aged over 50 years and mostly in women $[4,5]$. In line with the literature, the median age of our patients was 65 years and most of the patients were female $(74.2 \%)[4,5]$.
The exact etiology of RP remains unclear. Although conservative methods such as prevention of straining, constipation therapy, tape ligation, and injection of sclerosing solutions are performed particularly in old-age patients with comorbidities, most RP patients require additional surgical intervention [4]. The primary aim in surgical treatment of RP is to restore the physiology of impaired anatomical and 
defecation mechanism as much as possible. To achieve this, various surgical techniques including narrowing of the anal orifice, obliteration of the peritoneal pouch of Douglas, restoration of the pelvic floor, bowel resections, rectopexy, or combined approaches including one or several of these techniques have been recommended [4, 6-8].

Although patients with RP typically have a normal resting anal sphincter pressure, their maximum constructor pressure of the external anal sphincter is usually lower. As a result, the rectum often prolapses out of the anal canal during the period until the anus is closed. In turn, the arousal, perception, initiation and resting mechanisms of defecation are impaired due to continuous stimulation of impulses originating from the prolapsing and protruding rectal mucosa. Meaningfully, the more prolonged incontinence is, the more difficult it will be to eliminate. As a matter of fact, this is the most challenging issue for surgical treatment; even if the anatomic integrity can be achieved by surgical treatment, functional outcomes can be disappointing [9$11]$.

In our patients, transabdominal surgeries were conducted via open or laparoscopic approach and the most commonly performed technique was rectopexy with the use of polypropylene mesh. As the present study aimed to investigate the effect of open and laparoscopic approaches on patients' quality of life, transanal approaches were excluded.

Rectal prolapse (RP) leads to significant social and functional problems including sexual dysfunction [12]. Additionally, constipation and fecal incontinence are commonly seen in the patients $[13,14]$. All these conditions may result in direct or indirect financial and social problems for the patients. Besides soiling of clothes, RP also leads to loss of labor [15] and more importantly to negative effects on patients' quality of (loss of self-respect, embarrassment, depression, increased personal needs, organizing a life around easy access to the bathroom, and avoiding recreational activities) [16].

Laparoscopic rectopexy is a popular minimally invasive technique due to its advantages concerning shorter length of hospital stay and early oral intake [17]. In our study, although both groups had similar outcomes at the end of postoperative month 6, laparoscopic rectopexy provided more beneficial outcomes compared to open surgery at postoperative week 1 in terms of length of hospital stay, early complications, and early GIQLI scores. In line with the literature, the incidence of local complications in our study was higher in the open group compared to the laparoscopic group (17\% vs. $7.1 \%)$. In the literature, the rates of morbidity after open surgery have been shown to range between 8-26\% [18]. In 1995, Eypasch et al. The GIQLI quality of life index, developed by GIQLI for use in gastrointestinal diseases, has been shown to positively contribute to the quality of life in the postoperative period, especially with the development and widespread use of laparoscopy, with laparoscopic cholecystectomy $[19,20]$ and laparoscopic colectomy $[21,22]$.

\section{CONCLUSION}

The present study investigated the effect of surgical approaches (open and laparoscopic) on the quality of life of RP patients using GIQLI. The results indicated that although both groups had similar preoperative GIQLI scores, the laparoscopic group had higher scores at postoperative week 1. At postoperative month 6 , on the other hand, the groups had similar scores while their scores had increased significantly when compared to their preoperative scores.

Rectal prolapse (RP) has significant adverse effects on patients' quality of life, and surgery remains the method of choice for its treatment. Our results indicated that both open and laparoscopic approaches led to a significant improvement in patients' quality of life and that this improvement occurred at an earlier time in the laparoscopic group compared to the open group although their long-term outcomes were similar.

\section{REFERENCES}

1. Riansuwan W, Hull TL, Bast J, Hammel JP, Church JM. Comparison of perineal operations with abdominal operations for full-thickness rectal prolapse. World J Surg 2010; 34(5): 1116-22.

2. Akcan A, Sözüer E, Akyıldız H. Tam kat rektal prolapsus cerrahi tedavisinde rektopeksi ve rektopeksi ile birlikte sigmoid rezeksiyonun karşılaştırılması. Ulusal Cerrahi Dergisi. 2007; 23(2): 54-7.

3. Eypasch E, Williams JI, Wood-Dauphinee S, Ure BM, Schmülling C, Neugebauer E, Troidl H. Gastrointestinal Quality of Life Index: deveopment, validation and application of a new instrument. $\mathrm{Br} \mathbf{J}$ Surg. 1995; 82(2):216-22.

4. Corman ML, Aliison SI, Kuehne JP. Rectal Prolapse. Solitary Rectal Ulcer, Syndrome of the Descending Perieum and Rectocele. Handbook of Colon and Rectal Surgery 4th ed. Philadelphia, Lippincott Williams \&Wilkins. 2002; 17: 246-77.

5. Current Surgical Therapy 6. edition, Cameron JL, Mosby, Philedephia; 2001.

6. Çalıskan C, Korkut AM, Frrat Ö, Akgün E, Osmanoğlu H. Rectal prolapse experience: 68 cases in 27 years. Ege Journal of Medicine. 2008; 47(1): 29-34.

7. Akgün YA, Demirel AH, Kapan M, Öktem Ö, Öngören AU, Tezel S. Rektal prolapsusun tedavisinde rektopeksinin yeri. Ankara Eğitim ve Araştırma Hastanesi Tıp Dergisi. 2004; 37(1): 37 41. 
8. Steele SR, Goetz LH, Minami S, Madoff RD, Mellgren AF, Parker SC. Management of recurrent rectal prolapse: surgical approach influences outcome. Dis Colon Rectum. 2006; 49(4): 440-45.

9. Boutsis C, Ellis H. The Ivalon sponge wraps operation for rectal prolaps. Dis col rect 17: 21; 1974

10. Hawley P. Procidentia of the rectum .Ivalon sponge repair. Dis col rect 18:461-63 1975

11. Beahrs OH. Procidentis. Surg treatment. Dis col rect.1972; 15: 337.

12. Artibani W, Stuart L, Stanton D, Kumar R. Pelvic flor reconstruction. Urology. 2002;42(1):281-89.

13. Corman ML, Colon and Rectal Surgery, 3rd Ed. JB Lippincott Company; 1993.

14. Birnbaum E, Stanim I, Rafterty. Pudenta INerve Terminal Motor Latency İnfluences Surgical Outcome in Treatment of Rectal Prolapse. Dis Colon Rectum. 1996;39:1215-21.

15. Xu X, Menees SB, Zochowski MK, Fenner DE. Economic cost of fecal incontinence. Dis Colon Rectum. 2012; 55: 586-98.

16. Meyer I, Richter HE. Impact of fecal incontinence and its treatment on quality of life in women. Womens Health (Lond). 2015; 11: 225-38.
17. Benoist S, Toffinder N, Gould S, Chang A, Darzi A. Functional results two years after laparoscopic rectopexy. Am J Surg. 2001; 182(2): 168-73.

18. Kim DS, Tsang CB, Wong WD, Lowry AC, Goldberg SM, Madoff RD. Complete rectal prolapse: evolution of management and results. Dis Colon Rectum. 1999; 42(4): 460-69.

19. Finan KR, Leeth RR, Whitley BM, Klapow JC, Hawn MT. Improvement in gastrointestinal symptoms and quality of life after cholecystectomy. Am J Surg. 2006;192 (2):196202.

20. Keus F, De Vries J, Gooszen HG, Van Laarhoven CJ. Laparoscopic versus small-incision cholecystectomy: Health status in a blind randomised trial. Surg Endosc. 2008;22(7):164959.

21. Stucky CC, Pockaj BA, Novotny PJ. Long-term follow-up and individual item analysis of quality of life assessments related to laparoscopic-assisted colectomy in the COST Trial 93-46-53 (INT 0146). Ann Surg Oncol. 2011;18:2422-31.

22. Li J, Chen $\mathrm{R}, \mathrm{Xu}$ YQ. Impact of a laparoscopic resection on the quality of life in rectal cancer patients: results of 135 patients. Surg Today. 2010;40:917-22. 